\title{
Rethinking 21st Century Professional Development
}

\author{
Susan Gibson ${ }^{1}$, Charmaine Brooks ${ }^{2}$ \\ ${ }^{1}$ University of Alberta, ${ }^{2}$ Educational Consultant \\ Edmonton, $A B$, Canada
}

\begin{abstract}
In this paper we conceptualize and describe the key characteristics of a model for technologymediated professional learning that capitalizes on the affordances of our digital age while fostering a culture of professional inquiry and discernment. Our interest in this area arises from insights gathered from teachers, school administrators and districtlevel professional development providers during a 2005 study of the professional development experiences provided to guide the implementation of a new curriculum in a local school district. The participants' stories pointed to PD experiences that were limited in their effectiveness due to content overload, lack of applicability to the class, poor timing requiring teacher pull-out from the classroom, lack of attention to teachers' concerns, and, teacher resistance to change. Recommendations were made that the district may wish to consider online teacher professional development as a way to allow more teacher control of their own professional learning in terms of timing, content and accessibility. A recent survey of research on the field points to a shift to a technology mediated professional learning model that makes better use of the evolution of the Web.
\end{abstract}

\section{Introduction}

It has long been recognized that teacher professional development is essential to bringing about change at the classroom level. Not only does effective professional development allow teachers to increase their knowledge about new curriculum and develop new instructional and assessment practices [11], but also it can and should lead to improvements in student learning [1] [3] [10]. However, professional development is a complex, multilayered process that needs to be highly individualized. Furthermore, it is imperative that the culture of professional learning reflects the latest technologies. Given the affordances of our digitally connected world, we posit for example that teachers could engage in more relevant, engaging professional learning via social networks. New ways of thinking about technology mediated teacher professional learning such as this and others are explored further in this paper. We also posit a different way of thinking about teacher professional learning - one that is based on three guiding principles. These principles are a) begin with the people engaging in the professional learning, b) base professional learning inquiry on evidence collected from people's practice, and c) build a discerning and collaborative professional culture to support that inquiry.

\section{The problem}

Our interest in teacher professional development arose from our recent involvement in an extensive, focused research study examining the effectiveness of a professional development program to support implementation of new social studies curriculum in one Canadian province. While the study at the heart of this inquiry was done in one relatively small, urban district in western Canada with 6,500 students, 3,500 teachers and 13 schools, the implications of our findings are more far reaching. The data including teacher surveys, student and teacher interviews, classroom observations and document analysis, revealed that while the school district in question invested significant resources to ensure all the teachers were given similar in-servicing about the new curriculum (including three half-day, large group pull-out sessions), implementation occurred on a broken front. Some of the concerns raised by the teachers regarding their professional development experiences were: little applicability to the classroom; content overload; a 'one-size fits all' approach; no modeling, practice and follow up; having to leave their classrooms to participate; lack of teacher buy-in and of school level support after the professional development event; and, minimal administrator awareness of the curriculum change.

The teachers in our study recommended that implementation of new curriculum or any educational initiative for that matter should be envisioned as a dynamic, and at times disconcerting, process of adapting, shedding and acquiring practices. They claimed that teacher identity was at stake whenever changes were made to their practice and that teachers needed to feel confident and competent with the new curriculum before trying it out in their classrooms. Having someone demonstrate how to implement new strategies in the classroom and then having opportunities to practice and get follow-up feedback were absolutely essential in that regard. They also recognized professional development as a multifaceted process in which there needed to be recognition of the importance of school level support including having knowledgeable and 
encouraging administration to support teacher buyin, having an experienced "go-to" person on staff who could answer questions and concerns, and having regular opportunities to share ideas and resources with other teachers. They suggested that there also needed to be more attention given to the amount of constant change teachers experience and cautioned that care needed to be taken to try to better balance competing initiatives. Lastly while there was a general acknowledgement that face-to-face professional development experiences were important, they also recommended looking for alternatives to the 'pull-out of the classroom' professional development model and suggested making better use of available technologies to avoid having to leave their classrooms.

Based on this last recommendation, we surveyed the field of professional development through the lens of appreciative inquiry to identify what is working well with an eye to conceptualizing what type of model would be effective using the technological affordances now available.

\section{What is known about effective teacher professional development}

Through our review of the literature on what we have learned over the years about effective professional development, we were able to identify several recurring features. These features included the importance of professional development experiences that were: ongoing and intensive; coherent and connected to broader school goals and to other professional development opportunities; content and curriculum focused; based on teachers' needs; delivered in ways that were meaningful and relevant through active learning, collaboration, modelling, and opportunities for practice and feedback; and, teacher controlled and administration supported [1] [3] [5] [10] [11] [14]. Also acknowledged was the importance of seeing professional development as something that extended beyond the 'event' by establishing a culture of learning in schools in which teachers' learning continued to occur throughout implementation of new curriculum and where a supportive and inspiring environment for testing new ideas and practises was fostered [9]. Thus the most effective professional development experiences were those that were designed to incorporate an in-school component that allowed educators to see and share their own and their students' work reflectively and collaboratively. While these are acknowledged as important and timeless features of effective professional development, not all professional development has been helpful, particularly when unfocused, disconnected from the realities of the classroom, imposed top down, not reflective of adult learning preferences, and lacking in intellectual challenge [3]
[9]. As well, traditionally professional development has been provided through a delivery-based, one-size fits-all approach that takes a training model and assumes a solution (e.g. improved skills and knowledge) to a known, common problem [4] [11] [12] [14] [17]. Thus the culture of teacher learning, like student learning, has been shaped by a way of thinking about learning as transfer of knowledge that is externally controlled [3] [4] [9].

Another common concern often identified by teachers in the research literature was a sense that their concerns were not being heard by professional develop providers. Teachers reported that traditional professional development experiences did not consider their current understanding, past experiences and specific interests. When this happens, the experience is not usually owned by the teachers and therefore is not recognized as directly relating to their particular classroom.

One final concern was the need to update this professional development approach relative to the changing realties and specifically the digital affordances of our time in ways that were more in tune with teachers' busy schedules, that provided access to otherwise difficult to locate and unavailable resources, and that provided support that was timely, ongoing and job embedded [6].

\section{Benefits of online teacher professional development}

While traditional professional development models were being scheduled within the constraints of available time within the school calendar, there was growing evidence that effective teacher learning was an ongoing, natural part of teacher practice. As well, much of their professional learning was localized. They tended to go to knowledgeable and experienced peers on their school staff or in their districts to exchange ideas and to get support for and help with initiatives that they wanted to experiment with in their teaching practice. Unfortunately much of this school-based knowledge remained untapped by the larger educational field. Consequently a shift to online teacher professional development was effective for capturing this local knowledge to share with the educational community at large.

The shift away from face-to-face big event professional development to individualized online teacher professional development also allowed for significant changes to professional learning that were more personally relevant, meaningful and engaging to teachers [12]. The use of electronic technologies allowed for web-based, interactive professional development experiences that included audio, text, video elements that were offered asynchronously so that they could be accessed whenever and wherever it was most convenient for the individual teacher. Such asynchronicity also allowed teachers to engage 
in a more reflective approach to their professional development experiences as they had time to think through questions posed and issues raised before posting a response online. This reflection on the learning experience and its relevance to the individual teacher's practice was often said to be missing in face-to-face experiences.

Using the technical affordances of Web 1.0, teachers were now able to: 1) have choices in their learning experiences (e.g. opting in and out), 2) take advantage of the flexibility of the technology (e.g. learn when and where it suits their schedules), 3) customize the experience (e.g. connecting with specific colleagues and researchers) and 4) have space to be reflexive [1][6] [8] [15] [21]. Another important feature was the opportunities for collaboration that online teacher professional development afforded. Not only could teachers benefit from engaging in online communities of practice with other teachers but some who were more reticent to share their ideas and engage in question posing in the traditional professional development model were now more likely to take part in virtual discussions and activities. Some were also encouraged by the fact that online interaction allowed the option of anonymity [6].

Thus, online teacher professional development, as part of a cultural shift in the way we engaged in learning, instigated active engagement rather than passive consumption of information. With the move away from large group, event focused professional development to individualized, just-in-time professional development, there was a significant change in thinking about what, how, why and when teachers learn. Here the thinking behind the purpose for engaging in professional development was beginning to shift.

Online teacher professional development also allowed for learning in a variety of contexts based on teachers' needs, interests and resources. Teachers could now share in their colleagues' work through example videos and simulations, sharing of lesson plans, and discussions about implementation of initiatives in the classroom [18]. Teachers also valued the way online teacher professional development created a place to learn disciplinespecific pedagogical approaches from and with their colleagues. The meaning of community in a networked age was extended and reimagined.

Video clips, selected and posted by teachers, were also seen as being particularly helpful in supporting reflective practice. Teachers were now able to collaborate with each other and share their reflections on a particular videoclip with an eye for its relevance to their practice, which made the learning experience much more meaningful.

Much like the professional development experiences mentioned where teachers on a specific staff were sharing resources and discussing the benefits of particular innovations with each other, through the online learning opportunities afforded by Web 1.0 technologies, now the teachers' community to learn with and from had expanded beyond the local school and district. Bringing a wider audience to the discussion added to the meaningfulness of the experience.

However, while there were significant shifts in the type of learning experiences that teachers could engage in through an online environment, these initial forays into online teacher professional development were restricted by the limitations of Web 1.0. In the early years of online teacher professional development much of the focus was on the technical framework, in large part due to the limitations of Web 1.0, and the professional development activities (e.g. webinars, videoconferencing workshops). That is, professional development developers worked with technicians to build online structures, experimenting with different platforms, and synchronous and asynchronous communication tools. Many of these early online experiences remained highly structured with the focus on delivering predetermined content and on the individual's acquisition of skills and knowledge often in a very isolated way. Online teacher professional development needed to be critically assessed to guard against the allure of the technology itself. In fact it seemed that many initial models of online teacher professional development foregrounded the technology and neglected to emphasize pedagogy.

However, most teachers were not easily enticed by technology and took a fairly pragmatic approach to professional development. They needed to feel that their valuable and scare professional development time was being spent productively and that their professional learning experiences were adding substantially to their understanding of how to make their practice more effective. Specifically teachers were looking for online experiences that were closely related to the curriculum they were teaching, student learning and effective teaching approaches. Being able to explore questions and issues relevant to their practice and then taking the ideas for improving practice arising from that exploration back to their classrooms was integral. Thus, the most successful online teacher professional development models were those that adopted an inquiry approach or were set in a specific pedagogical problem [6].

\section{Web 2.0 and beyond}

Increasingly research has noted a widening gap between how teachers (and students) live and learn in contemporary society outside and inside schools. Coupled with our growing understanding of the learning process, one of the key factors contributing 
to the reappraisal of our education system and professional learning is the expansion and diversity of technologies changing the way we access information, interact with others and build knowledge. Hand in hand with these changes views are recent changes in technology, especially the development of Web 2.0 and the growth of social networking, along with changes in our understanding about ways of learning are resulting in a shift from online teacher professional development to technology mediated professional learning which provides a more self-paced and flexibly responsive approach to the interests and needs of each individual [8]. This shift in orientation is significant. For example, Web 2.0 features allow for more participation, information sharing, collaboration and user-centred design.

With the shift to more responsive technology we also see a move away from a focus on 'professional development' which implies a deficit model (i.e. the need to be developed) based on an understanding of teachers contributing to improving organizational performance measures (e.g. student achievement scores, literacy rates and overarching systemic goals) with an emphasis on acquiring specific practices, externally generated knowledge and content driven design to 'professional learning' which implies ongoing growth, individual learning inquiries and goals are the focus, work that is taken up for learning's sake, content arises from experience of participant and teacher-constructed knowledge [9]. These changes are now recognized as being integral to the success of teacher professional development:

In order to reflect the current research, to change teaching practice, and to increase student achievement, professional development must be ongoing, job embedded, relevant to the teacher's instructional needs, and collaborative in nature. The advent of quality online professional learning combined with inperson, peer-based professional learning communities has enabled this approach to professional development to have the greatest success for increasing teaching quality and student learning [16].

Recent calls for reform or 'transformation' of education acknowledge the power of teachers as change agents, and suggest teachers need to be more actively engaged in making decisions about their professional learning [4] [5]. Thus effective professional learning models that reflect this new paradigm are focused primarily on building teacher capacity and transforming teacher practice [5].

Such a change in the purpose of professional development requires a shift in control from external, top-down management of professional development experiences toward teacher centred professional learning. The literature calls upon professional development to be re-orientated with the learner, in this case the teacher, at the center, rather than the event (conference), theme or subject (assessment for learning or mathematics). David Warlick uses the diagram below to illustrate how professional learning is organized around the teacher who 'pulls' information and expertise from a variety of sources using both traditional and technology-mediates mechanisms [20].

In addition to the technical affordances of our time and building on what we have learned about online teacher professional development, a more epistemological aspect is also influencing how we conceive of teacher professional learning. Distributed cognition, the idea that the process and the interactions through which knowledge is created constitutes learning, challenges some long held beliefs which considered learning as an internalized, one-person act. In conceptualizing the future of professional learning in this frame, the need to continue to shift from more consumptive, passive professional development to participatory, teacherdirected professional learning experiences also becomes more salient. Also, since we accept the primacy of teachers to initiating and sustaining systemic change, we believe professional learning must be viewed as a social construct which implies that teachers grow their own knowledge base as they share their knowledge among colleagues, both within and across schools. This implies that successful change requires not only attending to the important formal structures, but also to the informal networks of social relations that create webs of understanding, influence and knowledge prior to, during and after the implementation of a change strategy. Thus technology-mediated professional learning is grounded in, and must be evaluated in consideration of, this constructivist view of learning.

There is a strong correlative relationship between how teachers experience learning and how they practice their craft. Quite simply, how teachers engage in professional learning may serve to reinforce a supply/push teaching model. Changing deeply ingrained and strongly reinforce rituals of schooling will require professional learning experiences that are much more than the typical information exchanges and "make and take" approaches. Following this argument, one could assume the transformation of education will only occur after a transformation in professional learning. In addition to adopting a new way of thinking about teachers as $21 \mathrm{st}$ century learners, professional learning needs to work alongside the lived realities of working and learning in a networked age. Given this understanding, informal, technology-mediated 


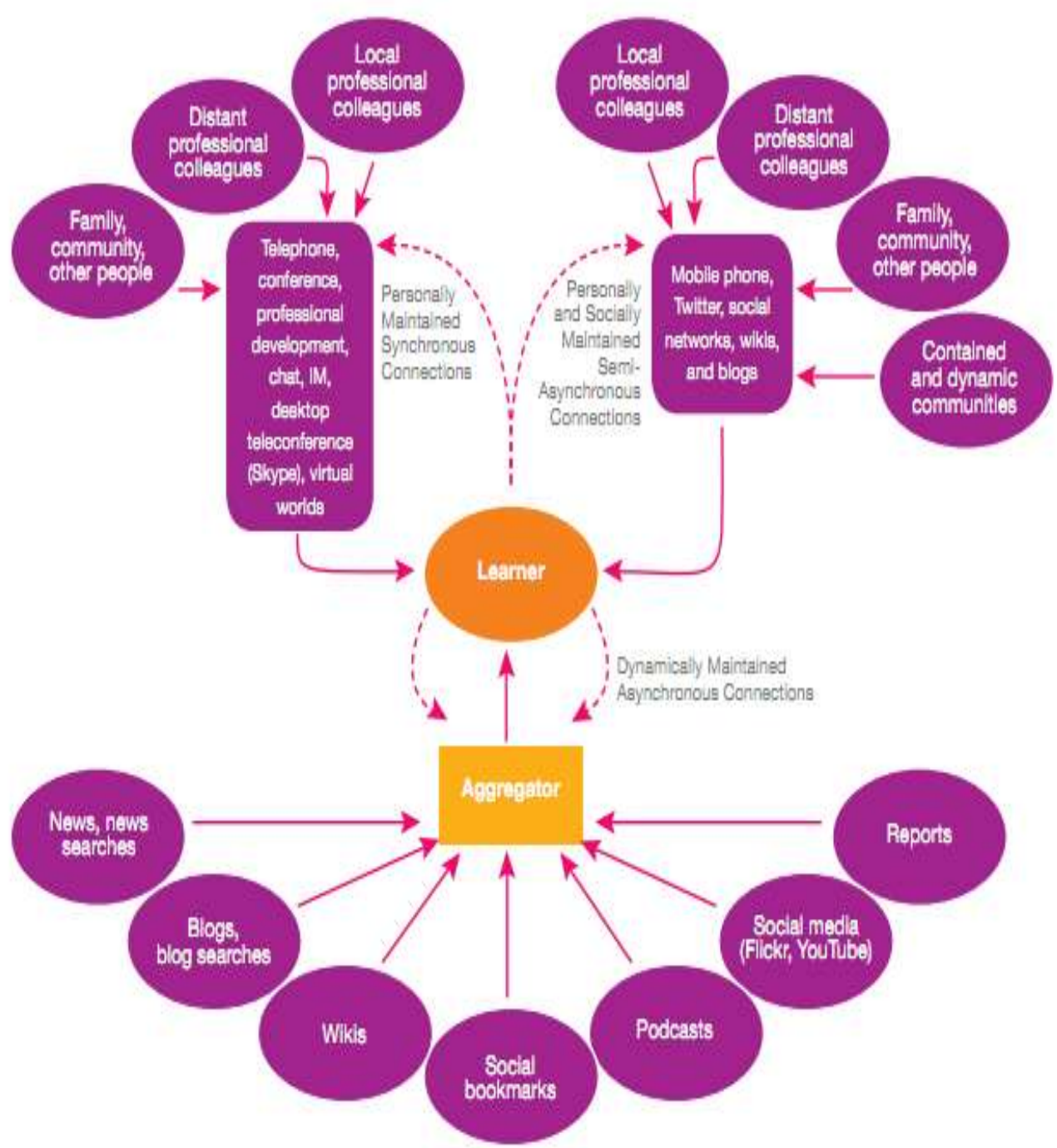

Figure 1. David Warlick's Model of the Networked Learner

models have the potential to facilitate professional learning when and where teachers need it.

Transforming schools into learning organizations, where people work together to solve problems collectively, is more than a question of inserting a new curriculum or a new program; it involves thinking through how the content and processes of learning can be redefined in ways that engage students and teachers in the active pursuit of learning goals - a joining of experiential learning and content knowledge. Teaching as telling, which has dominated pedagogy and the consequent organization of schooling and the way teachers see their work, is being called into question as professional learning for teachers increasingly connects to this reconsidered view of schools.

Technology mediated professional learning addresses some significantly different features from online teacher professional development that support this teacher capacity building and transformation in practice. These features include: less structured, customizable, technology-enabled networked learning; individual flexibility and choice in learning experiences (e.g. learn when and where fits schedule, opting in and out); emphasis on interactions occurring between colleagues resulting in coconstructed knowledge; emerging, teacher-initiated social media-based communities; and a culture of visible and accessible peer modeling enabled by technologies [2], [6], [8], [17], [18], [20], [21]. In this way, technology mediated professional learning allows modeling to be visible and accessible [19].

New evidence proves this shift in decision-making and ownership also positively impacts student achievement [5]. In addition, the changing conception of teachers' learning is mirroring the changing notions of student learning. Increasingly a widening gap is appearing between how teachers (and students) live and learn in contemporary society outside and inside schools. Coupled with our 
growing understanding of the learning process, one of the key factors contributing to the reappraisal of our education system and professional learning is the expansion and diversity of technologies changing the way we access information, interact with others and build knowledge.

...just as we have moved to Web 2.0, we must move to Learning 2.0, a demand-pull rather than supply/push teaching and learning model....demand-pull learning modes blur the lines between formal and informal education, and engages students in ongoing "flows of action" that are based on real world events that support passion-based learning. Whether one sees these calls for reform as a daunting task or breath-taking opportunity, as researchers and designers of TPD (technology-mediated professional development) we must respond to our changing world and changing focus of education [21].

While technology mediated professional learning is still in its infancy, there is evidence to suggest teachers are engaging in various forms of technology mediated professional learning already. In fact, learning is occurring organically online as individuals seek out support, resources and inspiration. Interestingly, one study found that in addition to participating in traditional, face-to-face professional development such as conferences and workshops, teachers in online communities, "were committing 1-3 hours per week in time...an additional 60-80 hours per year on professional learning. This time appears to be worthwhile and necessary to the professional lives of its members, (as membership was) maintained for 1-3 years" [7]. However, for technology mediated professional learning to be successful we must also recognize more systemic change and a cultural shift are required for future development of technology mediated professional learning. While a structure can easily be created online it will grow and become valuable only if a critical mass actively participates [17]. Emerging models of technology mediated professional learning acknowledge teachers are not drawn by the technological affordances of an online space, but rather participate out of a specific curricular or pedagogical need or for collegial support.

It will also be necessary to provide spaces for teachers to be more actively involved and critically engaged in the how, what and why of professional learning. Teachers will need to be professionally responsible for ensuring the professional learning in which they engage is beneficial and contributes to their professional growth. In effect, teachers must "start being professional learners - intensely critical of the professional development we participate in and condone [17].

It is increasingly apparent professional learning must reinforce teacher efficacy, change practice, enhance student learning and ultimately lead to systemic educational change. In this frame, the current means by which professional development is evaluated may need to be revisited. Technology mediated professional learning has the potential to support a shift in how we measure the impact of teacher learning and can deprivatize practice by providing powerful models of teaching practice and opportunities for embedded coaching. Perhaps predictably, the literature underscored the need for professional development to be embedded in teacher practice, to be ongoing, and to allow for collaboration and experimentation.

\section{Envisioning an effective technology mediated professional learning experience}

Derived from this review of the literature on effective professional development, in traditional face-to-face and online formats, we suggest a model for technology-mediated professional learning that effectively enhances teaching practice by capitalizing on the affordances of our digital age while fostering a culture of professional inquiry and discernment. Our model proposes three guiding principles that we feel should be a part of any technology mediated professional learning experience. These principles are: 1) focus on people, 2) gather evidence to guide inquiry, and 3) foster a discerning and collaborative professional culture to support that inquiry [4], [11] [12], [16].

Focus on the people. The professional development culture has ingrained an expert patient relationship as teachers have often been passive recipients of information and experts the purveyors of knowledge. Teachers, in this powerladen position, rarely contribute, question or make decisions about their own professional learning. They are not recognized as active agents of their own professional development. The need to shift from more consumptive, passive professional development to participatory, teacher-directed professional learning experiences also becomes more salient.

The shift in conceptions of learning from consumption of knowledge to construction necessitates a move away from event-driven, structured learning towards teachers being more actively involved in directing their professional learning. Specifically, there is evidence of a connection between how teachers learn and how they practice. Simply put, if professional development models reinforce an externally-designed, stand and deliver, non-participatory type of learning 
environment, teachers will be less likely to enact constructivist, inquiry-based learning practices, in keeping with 21st Century learning, in their classrooms. However, when teachers are able to experience a more personalized approach to learning that incorporates contemporary technologies and makes authentic connections to their practice, they are more likely to take up a similar approach with their students. In fact, the catalyst for the transformation of education, as envisioned by countless educational leaders, may lie in reimagining professional development as professional learning in a networked age. Therefore, our first guiding principle for effective technology mediated professional learning is that any professional learning experience for teachers has to originate with the teachers themselves not be provided for them by an external organization. It will increasingly be necessary to provide spaces for teachers to be more actively involved and critically engaged in the how, what and why of professional learning. In effect, teachers must become professional learners who are more critical of the professional development they participate in and condone [19]. Therefore, teachers will need to be professionally responsible and accountable for ensuring the professional learning in which they engage is beneficial and contributes to their professional growth, thereby taking control of their own personal professional learning. In this frame, teachers as professionals take responsibility to become engaged professional development planners, participants and learners by bringing their concerns, questions and prior experience to their learning experiences and growing their inquiry from there.

In this way technology mediated professional learning has the potential to facilitate a more discerning professional culture of teachers as agents of their own professional development.

Gather evidence. Given the distributed nature of learning and the autonomy of the participants, the technology mediated professional learning model we envision requires support, which relies less on physical/geographic organization structures and more on professional inquiries. These inquiries must originate from the teachers' practice. A core feature of support for implementation must necessarily address the 'so what' of professional learning. Evidence of impact, technology mediated professional learning can both assist in the collection of evidence of impact as well as providing the teaching community with powerful models of teaching strategies, approaches and insights.

Since the primary objective of teacher professional learning is improvement in student learning, teachers need to understand what they are doing well as well as what their students are doing well in the classroom. They also need to identify areas that need improvement, which can then become the target of their professional learning experiences [9], [15]. In the past, the professional development event or the resource (e.g. the inputs) was accepted as evidence of impact, but it is increasingly apparent professional learning must reinforce teacher efficacy, change practice, enhance student learning and ultimately lead to systemic educational change. Technology mediated professional learning has the potential to support a shift in how we measure the impact of teacher learning.

First, teachers working within the technology mediated professional learning environment will need to be provided with time for reflection and feedback from colleagues in determining the impact of their learning on their practice and on student learning. In order to facilitate this more intentionally, it would be valuable to include a research component, perhaps through a pilot study, within the implementation plan. In this way, data could be gathered and shared with the community throughout the life of the project. The technology mediated professional learning experience could focus on providing support around a topic or direction regardless of the location of participants. This feature of effective technology mediated professional learning calls for a shift from teachers 'doing' professional development to teachers deciding what experiences they need based on the evidence that they have gathered from their own practice.

Foster a discerning, collaborative professional culture. A third feature of effective technology mediated professional learning is a focus on establishing learning communities as places to foster rich learning spaces for teachers to hone their practice with their colleagues. This feature recognizes that there is an important symbiotic relationship between the individual learner and thriving learning communities. In this way, technology mediated professional learning is based on solving the classroom-specific problems identified by teachers by drawing on the shared knowledge base of colleagues.

In effect, though people perpetually explore online content and materials to learn, a final ingredient is needed to truly open education for more democratic participation and personalization. That component has to do with culture and psychology as much as technology. Thus, the third macro trend electrifying all of human kind today is the creation of a culture that collaboratively builds, negotiates, and shares such knowledge and information: a participatory learning culture [2].

Here too, however, as Jennifer Lock notes, in order for collaborative communities to be sustained the community members must hold the power and set the direction of the community rather than having it imposed on them [18]. There are many examples 
of beautifully designed but vacant online communities. The 'if-we-build-it-they-will-come' theory has been disproven and we now know participants need to find personal meaning in the community and facilitation can be key to engaging members and creating a thriving constructivist learning environment. The current technological affordances allow for learning communities to be built both within and beyond school boundaries. Thus a networked community allows for greater possibilities for learning both within and between schools. Indeed, one could argue the meaning of community in a networked age is being extended and reimagined. In the past, the term blended learning environments has been used to denote a combination of online and face-to-face teaching and learning experiences but a new term is beginning to surface in the literature which suggests a much more fluid environment.

Blended learning environments are generally clear - one is either online in some learning context, or one is face-to-face. Blurred learning environments occur in networked learning contexts because the learners are often working synchronously across distance and at the same time working face-to-face with a group. The meaning of being "present" blurs as one works across time and distance, and brings new dimensions of learning in networked learning environments [21].

Often times, in speaking of the value of professional learning networks, fantastic examples are cited which demonstrate how individuals can mine their networks for rich, just-in-time responses to any inquiry. "I posted the following message on Twitter: "Writing article about PLN. What's your favorite PLN tool - besidesTwitter... :-)" Over the next two hours, 33 Twitter-using educators from across the United States respondd..." [20]. The implication is that one can toss a query into the pool and ripples of wisdom will follow i close succession. Those new to social media will need realize that it takes time to develop a network. However, the platform is available and connections can occur quickly and exponentially. David Warlick notes that as individuals set out to build connections they are more likely to choose like-minded colleagues. While this is comfortable and certainly affirming, professional and personal growth is often fostered in challenging situations. He recommends that in order to ramp up the learning potential of these professional learning network, we need to cultivate ones that take us out of our comfort zone by challenging our thinking and frames of reference [20].

In addition to the technical aspect, that is being able to connect with others through networks, another more epistemological aspect also influences how we conceive of an online professional learning community. Distributed cognition, the idea that the process and the interactions through which knowledge is created constitutes learning, challenges some long held beliefs which considered learning as an internalized, one-person act. While this new way of thinking about learning and knowledge generation is an outgrowth of the potential of our networkedenvironment, it has roots in constructivism and the work of, for example, Vygotsky. The constructivist view of learning maintains that knowledge is emergent, viable and constructed by individuals not a fixed body of Truths to be transmitted and that this process of knowledge creation is a highly social and situated process. Meaning is made as individuals attempt to reconcile their own personal ideas with those of others that at times are dissimilar, resulting in new insights and new representations being formed. Learning from this perspective is a highly self-regulatory undertaking.

A final yet critical element of the collaborative professional culture is the active engagement of leadership in these communities. Instructional leaders can play a very significant role in helping to facilitating the learning potential of these communities by encouraging participation and sharing, helping to locate resources, and providing ideas for how to scaffold the learning. Educational leaders also must recognize that participants need time for reflection and feedback from colleagues in determining the impact of their learning on their practice and on student learning.

The leaders in a technology mediated professional learning setting may not be expert in the chosen area of interest, but rather would work alongside other participants as they build understanding and apply new insights. The leaders then would not be seen as a source of information but rather a facilitator of connections and a stimulator of critical, reflective practice. In addition to encouraging interactions and generating professional challenging dialogue, leaders can also play an essential role in identifying evidence of change in practice.

\section{Conclusion}

As is evident in this overview of the features of various forms of teacher professional development ranging from face-to-face to online and technology mediated professional learning, educational change is complex, iterative, social and political process. Reimaging how teachers learn could be integral to the systemic change if we are open to considering new models, refocusing the locus of control and establishing new metrics of effectiveness. The questions guiding our inquiry begin to build out possibilities for professional learning in a technology-mediated age. A cultural shift, from prescribed to customized, from mandated, formal to 
selected, informal, from situated to virtual, and from teacher development to teacher learning is required not only to realize a return on our professional development investment but also to ensure teachers experience learning in ways that are commiserate with the ways in which policy makers describe 21 st century learning. In this new space, the effectiveness of professional development is measured not by the number of attendees at a conference or the quality of the keynotes, but by how and in what ways teaching practice is influenced and ultimately student learning is enhanced.

As well it is increasingly apparent that professional learning must reinforce teacher efficacy, change practice, enhance student learning and ultimately lead to systemic educational change. Drawing extensively on the literature on online teacher professional development, we posit that effective curricular change models need to acknowledge the personal nature of professional learning and begin to capitalize more fully on the potential of technology broadly. If one accepts that much of what has been done in the name of professional development in the past is actually contrary to what we know constitutes effective learning experience, the urgent need for a bold approach becomes clearer.

In addition to the technical affordances of our time and building on what we have learned about online teacher professional development, a more epistemological aspect is now influencing how we conceive of professional learning. In conceptualizing the future of professional learning in this frame, the need to continue to shift from more from more consumptive, passive professional development to participatory, teacher-directed professional learning experiences also becomes more salient. The literature is clear: a plan to support technology mediated professional learning must reflect the type of professional learning culture we seek to grow.

\section{References}

[1] R. Blank, Alas N. de las. and C. Smith, C. "Does teacher professional development have effects on teaching and learning?" The Council of Chief State School Officers, Washington DC, 2008. Retrieved from http://hub.mspnet.org/media/data/Final_CCSSO_PD_final _cross_state_report_4_15_08_.pdf?media_000000002704. pdf (Access date: 6 May 2009).

[2] C. J. Bonk, The World Is Open: How Web Technology Is Revolutionizing Education, Jossey-Bass, San Francisco, CA, 2009.

[3] H. Borko, "Professional development and teacher learning: Mapping the terrain", Educational Researcher, 2004, 33(8), pp. 3-15.
[4] L. Darling-Hammond, "Developing professional development schools: Early lessons,

challenge, and promise. In Professional development schools: Schools for developing a profession, Teachers College Press, New York, 2005, pp. 1-27.

[5] L. Darling-Hammond, R.C. Wei, A. Andree, N. Richardson, and S. Orphanos, Professional learning in the learning profession: A status report on teacher development in the United States and abroad. National Staff Development Council, USA, 2009.

[6] C. Dede, D. Ketelhut, P. Whitehouse L. Breit, and E. McCloskey, "A research agenda for online teacher professional development", Journal of Teacher Education, 60(1), 2009, pp. 8-19.

[7] J. Duncan-Howell, "Teachers making connections: Online communities as a source of professional learning", British Journal of Educational Technology, 41(2), 2010, pp. 324-340.

[8] K. Fontichiaro, "Planning an online professional development module", School Library Media Activities Monthly, 25(2), 2008, pp. 30-31.

[9] M. Fullan, C. Cuttress, and A. Kilcher. "Eight forces for leaders of change", Journal of Staff Development, 26(4), 2005, pp. 54-64.

[10] M.S. Garet, A.C. Porter, L. Desimone, B.F. Birman, and K.S.Yoon, "What makes professional development effective?" Results from a national sample of teachers", American Educational Research Journal, 38(4), 2001, pp. 915-945.

[11] J. Gore, and J. Ladwig, "Professional development for pedagogical impact," Paper prepare for Australian Association for Research in Education Annual Conference, Adelaide, AU. Nov. 2006. Retrieved from http://www.aare.edu.au/06pap/gor06389.pdf (Access date: 5 May 5 2009).

[12] T.R. Guskey, "Professional development that works: What makes professional development effective?" Phi Delta Kappan, 84(10), 2003, pp. 748-767.

[13] S. Hirsh, and J. Killion, "When educators learn, students learn: Eight principles of professional learning", Phi Dela Kappan, 90(7), 2009, pp. 464-469.

[14] C. Huber, "Professional learning 2.0", Educational Leadership, 67(8), 2010, pp. 41-46,

[15] J. Killion, Assessing impact: Evaluating staff development. Corwin, Thousand Oaks, CA, 2007.

[16] Killion, J., \& Williams, C. (2009). Online professional development 2009. MultiMedia \& Internet@ Schools, 16(4) 8-10.

[17] M. Lebec, and J. Luft, "A mixed methods analysis of learning in online teacher professional development: A case report", Contemporary Issues in Technology and Teacher Education, 7(1), 2007. 
[18] J. Lock, "A new image: Online communities to engage", Journal of Technology and Teacher Education, 14(4), 2006, pp. 663-678.

[19] J. Perkins, "Personalising teacher professional development: Strategies enabling effective

learning for educators of 21 st century students", Quick, (113), 2010, p. 17.

[20] Warlick, D. (2009). Grow your personal learning network: New technologies can keep you connected and help you manage information overload. Learning \& Leading with Technology, 36(6), 5. Retrieved from http://landmark-

project.com/workshops/handouts/gypln_ll.pdf

[21] P. Whitehouse, "Networked teacher professional development: The case of globaloria", Journal of Interactive Learning Research, 21(4), 2010. 